QUALITY IMPROVEMENT REPORT

\title{
Effect of a scoring system and protocol for sedation on duration of patients' need for ventilator support in a surgical intensive care unit ${ }^{*}$
}

\author{
G Brattebø, D Hofoss, H Flaatten, A K Muri, S Gjerde, P E Plsek
}

Qual Saf Health Care 2004;13:203-205

See end of article for authors' affiliations

.....................

Correspondence to: Dr G Brattebø,

Anaesthesia and Intensive

Care, Haukeland

University Hospital,

N-5021 Bergen, Norway;

gbra@hele-bergen.no

\begin{abstract}
Problem: Need for improved sedation strategy for adults receiving ventilator support.
Design: Observational study of effect of introduction of guidelines to improve the doctors' and nurses' performance. The project was a prospective improvement and was part of a national quality improvement collaborative.

Background and setting: A general mixed surgical intensive care unit in a university hospital; all doctors and nurses in the unit; all adult patients (>18 years) treated by intermittent positive pressure ventilation for more than 24 hours.

Key measures for improvement: Reduction in patients' mean time on a ventilator and length of stay in intensive care over a period of 11 months; anonymous reporting of critical incidents; staff perceptions of ease and of consequences of changes.

Strategies for change: Multiple measures (protocol development, educational presentations, written guidelines, posters, flyers, emails, personal discussions, and continuous feedback) were tested, rapidly assessed, and adopted if beneficial.

Effects of change: Mean ventilator time decreased by 2.1 days ( $95 \%$ confidence interval 0.7 to 3.6 days) from 7.4 days before intervention to 5.3 days after. Mean stay decreased by 1.0 day ( -0.9 to 2.9 days) from 9.3 days to 8.3 days. No accidental extubations or other incidents were identified.

Lessons learnt: Relatively simple changes in sedation practice had significant effects on length of ventilator support. The change process was well received by the staff and increased their interest in identifying other areas for improvement.
\end{abstract}

O ne of the main reasons for treating patients in an intensive care unit is that they need ventilatory support, usually by sedation and endotracheal intubation. Continuous infusion of sedatives and analgesics prolongs ventilator time, increase in which can in itself be harmful. ${ }^{1}$ Optimal management of sedation can therefore both improve the quality of care and reduce the duration of need for intensive care. ${ }^{2}$

The "breakthrough method" is a tool for obtaining rapid improvements in medical care using multiple short cycle improvements. $^{34}$ It entails setting goals, choosing appropriate small changes, and measuring whether the changes do lead to improvements; if so, the changes are incorporated in the departmental routines. ${ }^{5}$ We wanted to reduce adult patients' ventilator time by use of a validated sedation scoring system and sedation guidelines. Before this project, the management of sedation in our unit was at the doctors' discretion.

\section{OUTLINE OF THE PROBLEM}

Patients with respiratory failure who need to be ventilated are normally given both analgesics and sedatives, commonly by continuous infusion. However, studies have shown that this practice prolongs ventilator time because patients tend to become too heavily sedated. ${ }^{126}$ Use of a sedation scoring system to ensure that sedation is sufficient but not excessive has therefore been recommended, and low rates of continuous infusion, with supplemental bolus doses, have been shown to reduce ventilator time. ${ }^{7}$

*This is a reprint of a quality improvement report that appeared in the $B M J, 2002$, volume 324, pages 1386-9.

\section{Setting}

The surgical intensive care unit at Haukeland Hospital, a university hospital with 1100 beds, has 10 beds and a staff of seven consultant anaesthetists, five residents, and approximately 60 registered nurses. During 1999 a total of 396 patients were treated in our unit, with a total length of stay of 2517 patient days, of which 1780 involved invasive or non-invasive ventilation. A postoperative recovery unit with 24 beds is attached to the main unit. Patients may be admitted to the intensive care unit directly or after 24 hours in the recovery unit. The project was part of a national quality improvement collaborative study in adult intensive care medicine, initiated by the Norwegian Medical Association. Our hospital was the largest hospital that specifically studied sedation and ventilator time, and which made a substantial advance. Since the interventions were primarily aimed at doctors and nurses there was no need for patient consent.

\section{ASSESSMENT OF PROBLEMS AND STRATEGY FOR CHANGE \\ Details of approach}

The project aimed to achieve a $20 \%$ reduction in the mean duration of patients' need for ventilator support by improving the management of sedation. Another goal was to provide the nurses with simple guidelines for adjusting the dosage of sedative drugs. ${ }^{8}$ We further wanted to raise the staff's general interest in the small scale rapid cycle improvement strategy. ${ }^{34}$ This meant using the "plan do study act" cycle (see fig A on bmj.com) and linking a number of such small scale qualitative experiments to obtain improvement over a relatively short time (see fig B on bmj.com). ${ }^{9}$ This approach 
is the so called "breakthrough" methodology developed and described by the Institute for Healthcare Improvement in Boston. $^{5}$

The project was carried out over a period of 11 months from December 1999. Cost containment was not a primary object.

\section{Development of guidelines}

A group of two doctors and two nurses developed simple guidelines for the sedative agents used in our department, midazolam and morphine, for their dosages, and for monitoring of sedation level. Before this project, we did not systematically assess or monitor level of sedation. For this purpose we chose the motor activity assessment scale (MAAS), which was translated into Norwegian and found easy to use. ${ }^{10}$

\section{INTERVENTION}

The sedation scoring system and a one page protocol for sedation were developed and initially tested on a small sample of patients in the intensive care unit. The protocol was based on recently published scientific papers and adjusted to meet the local needs and traditions. ${ }^{12810}$ They were then revised after the small scale experiments and questionnaires (table 1). After the modifications, the guidelines were copied on coloured paper and posted at each bed in the intensive care unit.

All adult patients ( $>18$ years) who were treated on a ventilator for more than 24 hours were to be sedated in accordance with the new guidelines. The doctors defined the level of sedation desired twice a day, and the nurse in charge of a patient was then responsible for monitoring the sedation level using the scoring system and was allowed to adjust sedation according to the guidelines. This was new, and increased the nurses' responsibility for control of sedation.

The new guidelines were introduced in several ways. The reasons for the changes in practice were thoroughly explained to all staff. The doctors were invited to discuss modifications after the guidelines had been presented to them at several meetings, to attain a local consensus. The project group also presented the guidelines to the nurses at several meetings. To reach all nursing shifts, three identical presentations were made to the nurses. During the meetings, the rationale behind monitoring level of sedation and the pharmacology of the drugs used were discussed. The guidelines were also distributed by post and by personal emails to the staff, and displayed on a wall poster centrally located in the unit, which was regularly updated with results from the project. We also introduced an "FAQ" section (frequently asked questions-a familiar internet feature) on the poster,

Table 1 Cycles performed to develop and implement sedation protocol (November 1999-February 2001)

\begin{tabular}{lll}
\hline Cycle & Action & No of patients \\
\hline 1 & Collection of baseline data & 147 \\
2 & First version of protocol discussed & \\
3 & Protocol trial & 4 \\
4 & Modification of protocol & \\
5 & Questionnaire survey 1 among staff & \\
6 & Data analysis & 52 \\
7 & Expanded trial & \\
8 & Questionnaire survey 2 among staff & \\
9 & Data analysis & 82 \\
10 & Change of opiate & \\
11 & Questionnaire survey 3 among staff \\
12 & Data analysis & \\
13 & Modification of protocol and implementation & \\
\hline
\end{tabular}

Table 2 Results before and after introducing simple guidelines for sedating patients receiving ventilator support. Values are mean (SD) unless indicated otherwise

\begin{tabular}{|c|c|c|c|}
\hline Characteristics & $\begin{array}{l}\text { First } \\
11 \text { months }\end{array}$ & $\begin{array}{l}\text { Last } \\
11 \text { months }\end{array}$ & $\begin{array}{l}\text { Difference } \\
(95 \% \mathrm{CI})\end{array}$ \\
\hline No of patients & 147 & 138 & \\
\hline Age (years) & $\begin{array}{l}55.8 \\
(17.6)\end{array}$ & $\begin{array}{l}52.3 \\
(16.6)\end{array}$ & $\begin{array}{l}3.5 \\
(-0.48 \text { to } 7.48)\end{array}$ \\
\hline $\begin{array}{l}\% \text { died in intensive } \\
\text { care unit }\end{array}$ & $\begin{array}{l}27 \\
(39 / 147)\end{array}$ & $\begin{array}{l}22 \\
(30 / 138)\end{array}$ & $\begin{array}{l}5.0 \\
(-0.5 \text { to } 14.9)\end{array}$ \\
\hline $\begin{array}{l}\text { Simplified acute } \\
\text { physiology score (SAPS II) }\end{array}$ & $\begin{array}{l}48.7 \\
(16.4)\end{array}$ & $\begin{array}{l}46.5 \\
(14.9)\end{array}$ & $\begin{array}{l}2.2 \\
(-1.45 \text { to } 5.85)\end{array}$ \\
\hline $\begin{array}{l}\text { Ventilator time } \\
\text { ( } 24 \text { h days) }\end{array}$ & $\begin{array}{l}7.4 \\
(7.5)\end{array}$ & $\begin{array}{l}5.3 \\
(4.5)\end{array}$ & $\begin{array}{l}2.1 \\
(0.65 \text { to } 3.55)\end{array}$ \\
\hline $\begin{array}{l}\text { Length of stay in } \\
\text { intensive care unit }\end{array}$ & $\begin{array}{l}9.3 \\
(8.7)\end{array}$ & $\begin{array}{l}8.3 \\
(7.5)\end{array}$ & $\begin{array}{l}1.0 \\
(-0.89 \text { to } 2.89)\end{array}$ \\
\hline
\end{tabular}

where important questions raised in discussions with the staff were answered. The project group also worked in the unit, making it possible for the staff to discuss at any time issues that might arise.

\section{Measurement of problem}

Baseline data were taken from the intensive care unit's clinical database (Regina), which has been in use for several years. ${ }^{11}$ Severity of illness was measured by the SAPS II scoring system. ${ }^{12}$ Ventilator time (measured in 24 hour days-for example, 6 hours $=0.25$ days), length of stay in the intensive care unit (in days), and mortality were also recorded. Our department has also operated a confidential reporting system for adverse events, making it possible to identify adverse effects that may be related to sedation practices. ${ }^{13}$ Data for each patient were collected and displayed graphically in the unit, allowing the staff to follow progress. Feedback was also provided regularly at staff meetings.

\section{Statistical analysis}

Data were analysed using statistical process control time series. Results were plotted in relation to time, to make direct visual evaluation possible. ${ }^{14}$ We calculated control limits for mean length of ventilation time before and after intervention and for length of stay in intensive care, and also mean differences and 95\% confidence intervals.

\section{Effects of change}

During the first 11 months of 1999 a total of 147 adult patients received ventilator support for more than 24 hours.

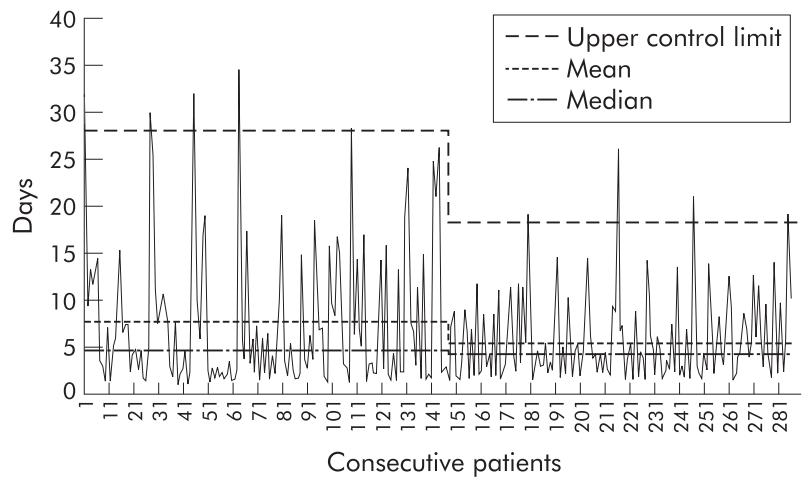

Figure $1 \quad \mathrm{XmR}$ chart for 285 consecutive adult patients ( 147 before and 138 after adoption of a sedation protocol and guidelines), showing reduction in daily average ventilator time and also in its variation (indicated by lowering of the upper control limit). 


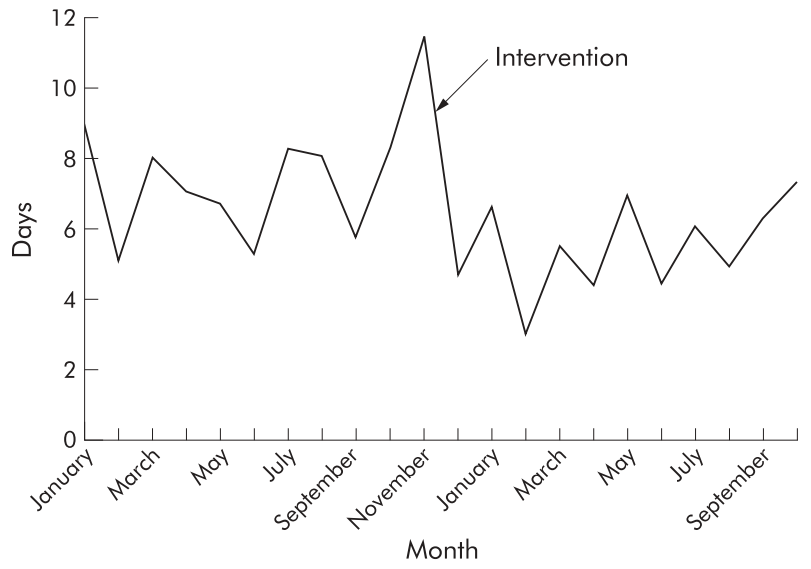

Figure 2 Mean monthly patient ventilator times before and after adoption of a sedation protocol and guidelines.

The data from these patients served as baseline. In the following 11 months a total of 138 patients were treated according to the new protocol (table 2). No other important changes took place in our unit or surgical services at the hospital in this period.

Mean ventilator time decreased by 7.4 to 5.3 days (28\%), and the mean length of stay was reduced from 9.3 to 8.3 days (11\%) (table 2). As the XmR chart (fig 1 of the postintervention period shows, not only was average ventilator time reduced, but also its variation, indicated by the lowering of the upper control limit. The process is still not statistically stable and its future average and variation limits cannot safely be predicted, as a clinical process like this is inherently unstable and some patients will need longer ventilator support. Our aim was not to standardise ventilator time: we only wished to reduce that part of the variation that might be ascribed to unwanted differences in management style among staff members. The reduced variation in mean ventilator time each month is also shown in figure 2 . The mortality in the unit declined (27\% in first 11 months, $22 \%$ in second 11 months). Data from the department's confidential reporting system did not indicate any adverse effects on the patients. Analysis of three short questionnaires answered by the staff did not reveal any major problems regarding the introduction and use of the new protocol.

\section{LESSONS LEARNT AND FURTHER STEPS}

By introducing a few relatively simple guidelines for the management of sedation in adult patients being mechanically ventilated, we were able to reduce mean ventilator time by nearly $30 \%$.

The main reasons for the success of this project were its specific and concise aims and an interprofessional approach. A dedicated project group and continuous follow up were also important. The medical and nursing directors' open support for the project and short weekly meetings to allocate tasks also contributed. Few data were needed, and these were easily obtainable. The wall poster with graphically displayed results served as an important information source and encouraged staff ownership of the process, and this in turn increased their commitment and willingness to change. The major challenge for the project group was to reach all staff members with information and answer their questions.

One factor that simplified our task was the availability of baseline data from the department's clinical database. The fact that the initiative came from the Norwegian Medical

\section{Key learning points}

- Introduction of a few relatively simple guidelines for management of sedation reduced the duration of adult patients' need for mechanical ventilation by nearly $30 \%$

- The need for extensive information during the change process should not be underestimated

- Documented achievement in quality projects encourage staff to identify other areas for improvement

Association and was not a cost cutting exercise by some agency with a financial interest was important for getting the staff involved. This gave the project credibility, especially among the doctors. Interprofessional collaboration has resulted in substantial quality improvements under such conditions. ${ }^{15}$

\section{Authors' affiliations}

G Brattebø, H Flaatten, A K Muri, S Gjerde, Department of Anaesthesia and Intensive Care, Haukeland University Hospital, N-5021 Bergen, Norway

D Hofoss, HELTEF, Foundation for Health Services Research, PO Box 55, N-1474 Nordbyhagen, Norway

P E Plsek, Paul E Plsek \& Associates, 1005 Allenbrook Lane, Roswell, GA 30075, USA

Funding: Norwegian Medical Association and Haukeland University Hospital.

Competing interests: PEP is also a senior fellow at the Institute for Healthcare Improvement (Boston, USA).

\section{REFERENCES}

1 Kollef MH, Levy NT, Ahrens TS, et al. The use of continuous i.v. sedation is associated with prolongation of mechanical ventilation. Chest 1998:114:541-548.

2 Kollef MH, Horst HM, Prang L, et al. Reducing the duration of mechanical ventilation: three examples of change in the intensive care unit. New Horiz 1998;6:52-60.

3 Marx WH, DeMaintenon NL, Mooney KF, et al. Cost reduction and outcome improvement in the intensive care unit. J Trauma 1999;46:625-630.

4 Plsek PE. Quality improvement methods in clinical medicine. Pediatrics $1999 ; 103: 203-214$.

5 Rainey TG, Kabcenell A, Berwick DM, et al. Breakthrough series guide: reducing costs and improving outcomes in adult intensive care. Boston: Institute for Healthcare Improvement, 1998.

6 Kreiss JP, Pohlman AS, O'Connor MF, et al. Daily interruption of sedative infusions in critically ill patients undergoing mechanical ventilation. N Engl J Med 2000;342:1471-1477.

7 Barr J, Donner A. Optimal intravenous dosing strategies for sedatives and analgesics in the intensive care unit. Crit Care Clin 1995;1 1:827-847.

8 Brook AD, Ahrens TS, Schaiff R, et al. Effect of a nursing-implemented sedation protocol on the duration of mechanical ventilation. Crit Care Med 1999;27:2609-2615.

9 Brock WA, Nolan K, Nolan T. Pragmatic science: accelerating the improvement of critical care. New Horiz 1998;6:61-68.

10 Devlin JW, Boleski G, Mlynarek M, et al. MAAS: a valid and reliable sedation scale for use with mechanically ventilated patients in an adult surgical intensive care unit. Crit Care Med 1999;27:1271-1275.

11 Flaatten H, Austlid I. Regina, development of a database concept in intensive care medicine. Acta Anaesthesiol Scand 1997;41(suppl 110):193.

12 Le Gall J-R, Lemeshow S, Saulnier F. A new simplified acute physiology score (SAPS II) based on a European/North American multicenter study. JAMA 1993;270:2957-2963.

13 Flaatten $\mathrm{H}$, Hevrøy O. Errors in the intensive care unit (ICU): results from one year anonymous registration. Acta Anaesthesiol Scand 1997;41(suppl 110):175.

14 Carey RG, Lloyd RC. Measuring quality improvement in health care: a guide to statistical process control applications. New York: Quality Resources, 1995.

15 Clemmer TP, Spuhler VJ, Oniki TA, et al. Results of a collaborative quality improvement program on outcomes and costs in a tertiary critical care unit. Crit Care Med 1999;27:1768-1774. 